
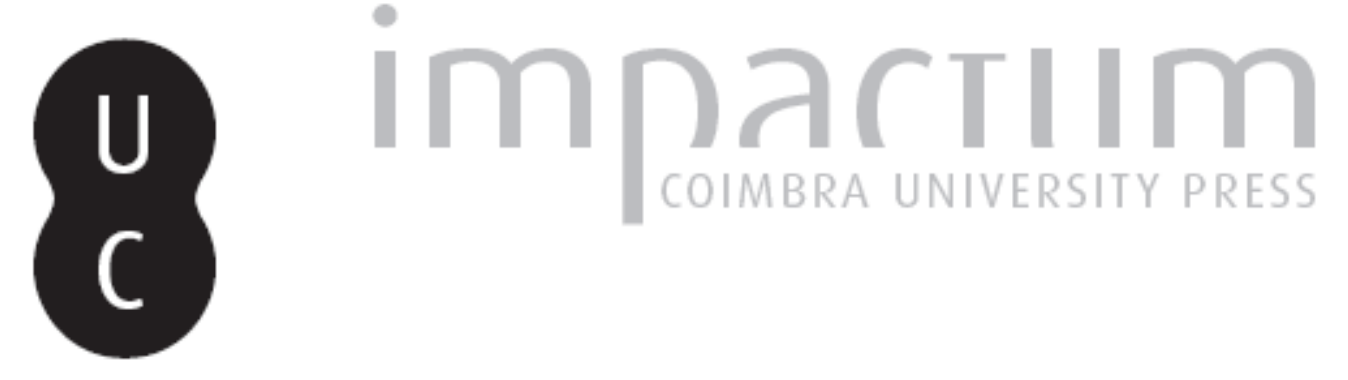

\title{
A definição de espetáculo em Sófocles: a correlação entre dramaturgia musical e a representação de figuras isoladas
}

\author{
Autor(es): Mota, Marcus
}

Publicado por: Sociedade Brasileira de Estudos Clássicos

URL persistente:

URI:http://hdl.handle.net/10316.2/37144

DOI:

DOI:http://dx.doi.org/10.14195/2176-6436_26-2_3

Accessed : $\quad$ 26-Apr-2023 11:59:10

A navegação consulta e descarregamento dos títulos inseridos nas Bibliotecas Digitais UC Digitalis, UC Pombalina e UC Impactum, pressupõem a aceitação plena e sem reservas dos Termos e Condições de Uso destas Bibliotecas Digitais, disponíveis em https://digitalis.uc.pt/pt-pt/termos.

Conforme exposto nos referidos Termos e Condições de Uso, o descarregamento de títulos de acesso restrito requer uma licença válida de autorização devendo o utilizador aceder ao(s) documento(s) a partir de um endereço de IP da instituição detentora da supramencionada licença.

Ao utilizador é apenas permitido o descarregamento para uso pessoal, pelo que o emprego do(s) título(s) descarregado(s) para outro fim, designadamente comercial, carece de autorização do respetivo autor ou editor da obra.

Na medida em que todas as obras da UC Digitalis se encontram protegidas pelo Código do Direito de Autor e Direitos Conexos e demais legislação aplicável, toda a cópia, parcial ou total, deste documento, nos casos em que é legalmente admitida, deverá conter ou fazer-se acompanhar por este aviso.

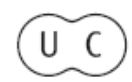




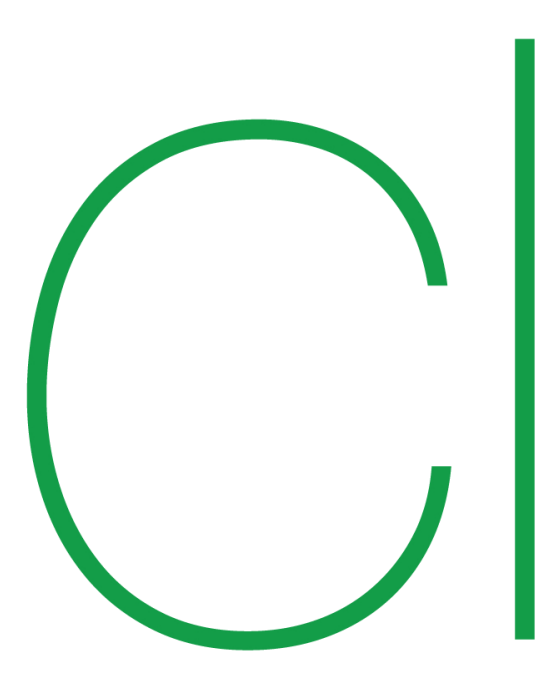

revista brasileira de estudos clássicos
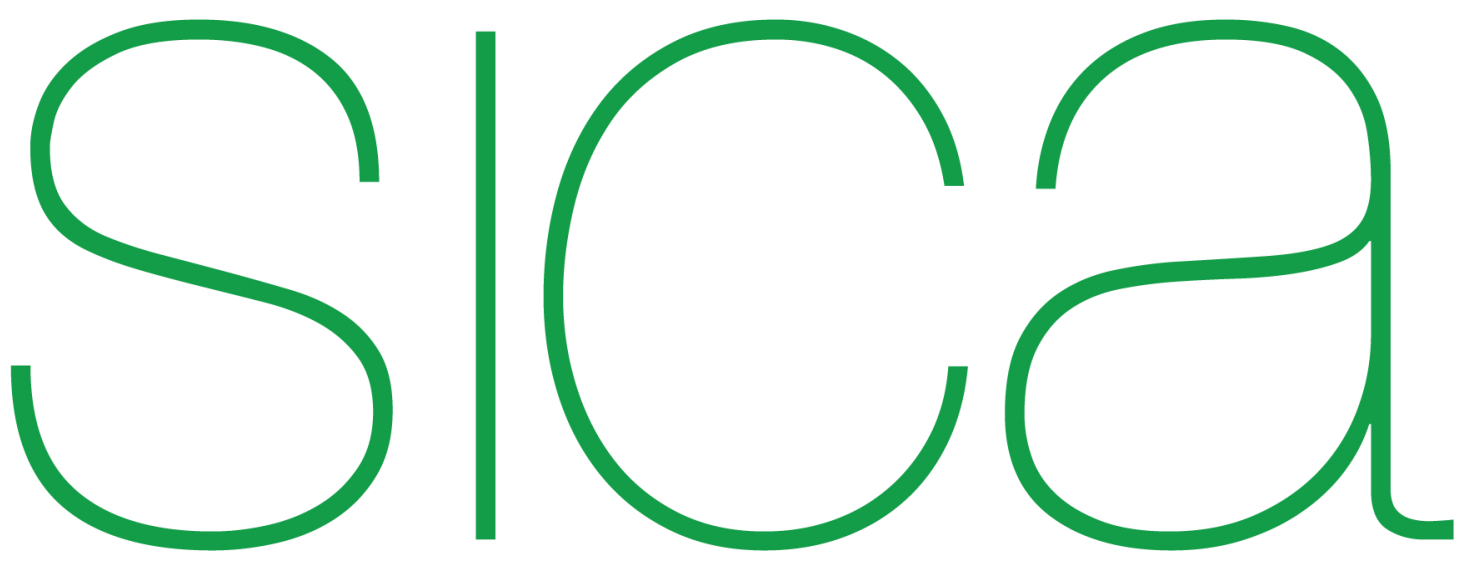

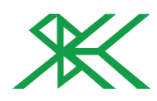

y

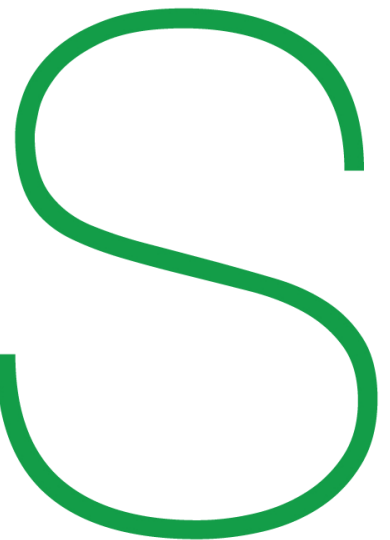




\section{A DEFINIÇÃO DE ESPETÁCULO \\ EM SÓFOCLES: A CORRELAÇÃO \\ ENTRE DRAMATURGIA MUSICAL E A \\ REPRESENTAÇÃO DE FIGURAS ISOLADAS ${ }^{1}$.}

Marcus Mota*

RESUMO: Na recepção moderna de suas obras, Sófocles é associado ao primado da personagem sobre o coro. Tal pressuposto de inspiração aristotélica é discutido e revisado a partir da forma como se dá a interação entre as partes faladas e as partes cantadas nos textos restantes de Sófocles.

PALAVRAS-CHAVE: Sófocles, Coro, Personagem.

ABSTRACT: In the modern reception of his works, Sophocles is associated with the primacy of the character over the chorus. This aristotelic-based assumption is discussed and reviewed from the interaction between spoken and sung section that we find in the remaining texts of Sophocles.

KEYWORDS: Sophocles, Chorus, Character.
*Universidade de

Brasília Laboratório de

Dramaturgia

1. Agradecimentos a FINATEC e DPP-UnB pelo financiamento das despesas com passagens e hospedagem. Trabalho apresentado no Congresso Internacional Sofocles el Hombre/Sófocles el Poeta. Málaga, 2003. 
A contribuição de Sófocles para o teatro ocidental tradicionalmente é sintetizada na rubrica personagem (Webster, 1936 e Easterling 1973). Tal primeiro plano personativo estaria relacionado a uma modificação da dramaturgia anterior, a de Ésquilo. Assim, segundo J. Herington (1982,p.12), "Sófocles e a maioria dos dramatistas que o sucederam por séculos após exibem a tendência de focar suas peças em indivíduos claramente delineados (outlined) e definidos, visíveis em cena".

Entretanto, este destaque à personagem, a uma figura não coral, apresenta-se muitas vezes como evidência não discutida na recepção crítica, o que acarreta uma compreensão reduzida da modificação operada por Sófocles na tradição dramatúrgica ateniense(Lesky 1983,Joansen 1962). Tal estratégia muito comum de se ampliar o escopo do conceito de personagem, atribuindo-lhe uma plenitude vivencial e não representacional, pode ser denominada de naturalização(Mota 2003). "Naturalizar a personagem" significa interpretá-la como se fosse uma pessoa, e não uma figura, uma construção. Ao se atribuir a uma personagem traços e expectativas relacionados a um indivíduo concebido em sua universalidade, há um deslocamento de foco da realidade do contexto da cena ou da trama imagética que especifica a construçáo da personagem para uma generalidade não associada a tal contexto. Mais claro: aquilo que está em cena não é uma pessoa no sentido de uma identidade civil: ela não fala como as outras pessoas falam fora de cena, ela não age como as pessoas agem fora do teatro, e ela se vê cercada de figuras que apenas existem, como ela, dentro do espetáculo.

A naturalização da personagem aplica à dramaturgia de Sófocles pressupostos do teatro literário do século XIX, teatro este baseado na palavra e em agentes dramáticos unificadores da cena, verdadeiras cabeças falantes. Tanto que Tycho Wilamowitz em seu livro sobre a técnica dramática de Sófocles procurou forjar uma solução para as chamadas inconsistências de enredo e de personagem(Wilamowitz 1917). Como resultado da aplicação de uma concepção mentalista do agente cênico ao teatro de arena grego, Wilamowitz, resolveu acomodar as flutuaçóes e sacrificar a definição de dramaturgia de Sófocles. Para Wilamowitz, Sófocles não trabalha com coerência global do espetáculo e nem com a consistência ideacional da personagem. Ao invés de modificar suas estratégias interpretativas, Willamowitz ratifica esta aplicação anacrônica ao explicar que 
a inconsistência personativa e a incoerência da totalidade da representação são o melhor de Sófocles. As sutilezas de pensamento advindas dessas inconsistências garantiriam o prazer intelectual da audiência. Em suma, a dramaturgia de Sófocles teria a seguinte definição:" a consistência de personagem seria inteiramente dispensável e a efetividade da cena individual seria considerada mais importante que a consistência lógica da peça como um todo ${ }^{2}$ "

Esta conclusão alinha-se à reação de Wilamowitz às discussóes psicológicas das peças de Sófocles. Procurando reverter a desconsideração do contexto dramatúrgico destas discussóes, Wilamowitz acaba por inverter a argumentação naturalizante da personagem ao propor a cena individual como horizonte da experiência da audiência e da composição. Em fim, por meio da proposição de um centro subjetivo ou da cena isolada, há sempre uma atomização daquilo que se analisa, a busca de um primeiro plano explicativo de obras dramáticas.

Contudo, durante a própria dramaturgia ateniense a questão do insulamento de algum elemento cênico foi utilizada como anticritério. Em As nuvens 1366-1367, Strepsíades apresenta os comentários de seu filho Fidípides após a aprendizagem da discursividade argumentativa sofista: "pois eu considero que Ésquilo é entre os poetas trágicos o primeiro, mas tem uma linguagem ruidosa, incoerente (sem estrutura), bombástica, um criador de palavras pomposas."

Tal julgamento de As Nuvens ecoa e amplia-se em As râs a partir do ataque de Eurípides à dramaturgia de Ésquilo ${ }^{3}$.

Mas Aristófanes, para superar as parcialidades dos litigantes, propóe nessa obra um plano de análise das obras dos dramaturgos ${ }^{4}$, que após as acusaçóes iniciais será seguido: os estudo das partes faladas e das partes cantadas, os nervos, as cordas que movem a tragédia.

É para uma dramaturgia musical, para a complexa integração entre partes cantadas e partes faladas que o embate entre os dramaturgos é contextualizado. $\mathrm{O}$ foco não reside na identificação de uma cena unificada seja por um centro subjetivo, seja por qualquer outro elemento em destaque. Para uma dramaturgia em ação, como aquela julgada em As rãs, não há a pressuposição de horizonte explicativo de tudo que é mostrado em cena. Tal atitude que transforma fatos repre-
2. Dawe 1963,p.22. Dawe procura reabilitar o método de Wilamowitz e aplicá-lo a Ésquilo, procedimento este seguido também por Court 1994. Note-se a correlação entre a dramaturgia de Ësquilo e de Sófocles através da utilização dos mesmos pressupostos de análise.

\section{As rãs 836-839.}

4. Russo 1994,p.209
comenta a expressão como
pertencente ao espetáculo
das marionetes, "as cordas
pelas quais a tragédia é
movida, que fazem com
que ela atue."

4. Russo 1994,p.209 pertencente ao espetáculo das marionetes, "as cordas movida que fazem com que ela atue." 
sentacionais em feitos ideacionais carece de apoio a partir da apreensão global da composição, realização e recepção de ficçôes audiovisuais da tradição ateniense.

Assim, todos os elementos que destacamos em nossas análises - personagem, cena - estáo na verdade subordinados a uma dinâmica representacional que se baseia em diferenças articulatórias, na relação entre partes cantadas e partes não cantadas. A diferença de tratamento desses elementos refere-se a mudança dessa dinâmica representacional. O diverso modo de se apresentar um personagem em Sófocles em relação a Ésquilo explicita não o estatuto do personagem, mas uma nova correlação entre as partes cantadas e não cantadas. É a alteração dessa correlaçáo que gera os efeitos a escolha e disposição dos elementos.

Assim, a diminuição das partes corais e aumento do número de versos das peças a partir de Sófocles não se explica pela emergência de uma dramaturgia da personagem. O extranumerário aponta para uma definição de espetáculo que modifica definição anterior. Ou seja, o fato de haver mais versos falados a partir de Sófocles nos textos restantes das tragédia grega não nos autoriza a apontar nesta informaçáo um aumento da importância das figuras individuais em cena e suas partes faladas em inversa relação ao status do coro e seus versos cantados/dançados. O que está em jogo é esta conexáo entre os dados textuais e a defesa da importância maior de uma figura isolada.

A unificação da cena através de centro subjetivo, essa identidade entre articulador da cena e o espetáculo mesmo, apaga toda a amplitude de uma dramaturgia musical e inibe a contextualização de uma tradição dramatúrgica que se efetivou através da apropriação e alteração de processos criativos específicos. Pois ainda assim, com as mudanças nas estatísticas da relação entre versos não cantados e versos cantados a partir de Sófocles, a tragédia grega continua com situaçóes e agentes coletivizados. Um caminho é reinterpretar os dados para além de um mote evolucionista que caracterizaria a história da dramaturgia ateniense como um processo contínuo de superação de seu núcleo primitivo baseado em atividades corais.

Inicialmente, para melhor nos aproximarmos da definição de espetáculo em Sófocles, torna-se preciso notar as implicaçóes de uma dramaturgia que não trabalha mais com 
trilogias conectadas. Com peças conectadas, Ésquilo preocupava-se em atualizar em cena o encaixe, a pertença, o vínculo do que se mostra a um horizonte amplo de referências. A interação entre cena e audiência se impunha através da assincronia entre eventos em cena e fora de cena. Evitando a identidade entre o conhecimento dos agentes dramáticos e o conhecimento que a audiência teria do espetáculo, Ésquilo promovia o alheamento da personagem quanto ao seu contexto de cena mais imediato. A partir disso, a teatralidade do espetáculo era exibida, a predominância da função representacional de seus agentes dramáticos sobre sua funçáo de caracterização. A perspectiva ampla da cena exibia os suportes teatrais do espetáculo, os meios mesmos de expressão. Este excesso metarefencial, essa performance sobre a performance concretizava a amplitude trilógica para a qual os atos em cena se dirigiam (Mota, 2008).

Já com Sófocles a composição e realização de espetáculos não conectados vai exigir diversos procedimentos, e, disto, uma outra definição. A partir da mesma base de correlaçáo entre partes cantadas e náo cantadas é que a dramaturgia de Sófocles vai se definir.

Sendo já a performance autoreferente e desvinculada de uma amplitude trilógica, não há a necessidade de se prover $\mathrm{e}$ exibir os nexos metareferenciais. A cena deixa de ser predominantemente um lugar de emergência de eventos extracena. Uma maior sincronização entre os atos em cena é realizada, acarretando um maior número de contracenaçóes entre os agentes dramáticos.

Entretanto, esse incremento da sincronização do tempo de exibição com o tempo dos eventos e das contracenaçóes radicaliza um movimento impresso em dramaturgias trilógicas: o esvaziamento de uma perspectiva hegemônica em cena. Tanto em dramaturgias trilógicas quanto não trilógicas há uma pluralidade de níveis referenciais que impedem a magnetização cênica - a total identidade entre representação e platéia - e atuam diretamente sobre a duração e extensão do que se mostra.

Assim, mais próximos e mais diretamente vinculados, os agentes manifestam mais e mais seus desacordos e sua não interação. Dessa forma, o espetáculo prolonga e alcança sua duração em uma continuidade que dissocia irreversivelmente os partícipes dos encontros personativos. A sucessão de con- 
5. Aponto as passagens abaixo como pontos de partida para detalhamento e expansão dos argumentos apresentados neste artigo. tracenaçôes de reduzida interação em meio a tantas ocasióes de aproximação e confronto, ao mesmo tempo que foca os eventos representados nos agentes que os desempenham, demonstra a incompletude mesma desse universo representado. $\mathrm{O}$ excesso da não concordância e conseqüente insulamento das figuras em cena desloca a compreensão do que se representa dessas figuras. As individualidades em cena, as figuras isoladas antes que o destaque para si próprias nos remetem para um paramovimento que as integra. Líquidos imiscíveis apontam para a totalidade da mistura.

E onde se torna mais inteligível esta outra perspectiva que o excesso de contracenaçóes dissociativas produz? Ora se o insulamento da personagem é um efeito desse excesso, não é no resultado que encontramos a compreensão global do processo.

Creio que é na macroestrutura do espetáculo, nas relaçóes entre partes cantadas e não cantadas, que temos uma esclarecimento efetivo dessa 'outra perspectiva' basilar para a compreensão da definição do espetáculo de Sófocles.

Em Sófocles a alternância entre as partes cantadas e não cantadas está em um diverso contexto daquele de Ésquilo. Não só há uma maior número de versos falados como também um maior número de encontros verbo-musicais entre personagens e o coro por peça ou encontros musicais com maior numero de partícipes.

Dessa forma, as fronteiras entre funçóes dos agentes e partes do espetáculo são remodeladas. O coro-corifeu participa das cenas dialogadas tanto marcando as mudanças de interlocução, entradas de personagens e, disto o design das contracenaçóes, quanto intensificando as divergências e o particularismo dos agentes, ao se referir a cada agente em cena. Já as personagens não corais cantam mais que em Ésquilo, pois cantam com o coro, cantam mesmo no párodo, cantam com outros personagens ou se insulam em seu canto mesmo dentro de encontros verbo-musicais. Nas partes faladas mesmas, os agentes dramáticos se justapóem por meio da maior presença do verso compartilhado (antilabê).

Exemplificando 5 :

1. em Antígona temos no párodo (vv. 100-161) uma performance coral na qual os pares estróficos são intercalados com estrofes anapésticas, exibindo uma atividade musical desdo- 
brada e divisão da perspectiva coral. Tal desdobramento por meio de estrofe anapéstica intercalada é depois retomado no Kommos com Antígona (vv.801-805) e na abertura do Kommos com Creonte (vv.1257-1260) e em vários momentos não musicais da peça (coro, vv.376-385 e vv.526-530, Antígona vv. 929-943) para figurar auralmente o insulamento, dentro de uma continuidade articulatória, de perspectiva personativa. Assim, as estrofes anapésticas deixam de ser uma abertura da performance coral para atravessar todo espetáculo e marcar insulamentos personativos.

2. Em Édipo Rei, a regularidade da música, construída sem estrofes intercaladas ou interrupçáo dos pares estrofes, entrechoca-se com a vertiginosa e crescente revelação da história de Édipo, até que em um Kommos perto do fim da peça Édipo canta e se apropria da música do coro - que apenas fala -, demonstrando ser ele mesmo a total presença audível e visível de sua desgraça, (como Hércules em As Traquínias vv.1004-1273). O contraponto entre a ordenação e regularidade estrófica e a série de revelaçóes aponta a para continuidade de um padrão que subage em meio aos eventos.

3. Em Ajax o párodo vincula-se logo a uma epirrema entre Tecmessa e o coro, com intercaladas estrofes anapésticas, o que promove uma sobreposição de formas que procura efetivar uma maior cotidianeidade mesmo em ambiente sonoro musical. As interrupçóes integram o canto à cena, tanto que no Kommos entre Ajax, coro e Tecmessa (vv. 348429), Ajax desponta com maior número de versos e no Kommos entre Coro e Tecmessa (vv. 879-960), após novo párodo (epipárodo), o coro desintegra sua performance durante a ação de encontrar o corpo de Ajax.

4. Em Filoctectes, o párodo é articulado com estrofes intercaladas de Neoptólemo. Neoptólemo interfere diretamente na performance coral como depois o fará na Ode ao sono (vv. 827-864), quando intercala ao canto do coro dáctilos hexâmetros e ao fim interrompe a ode mesmo com fala (v. 865). A atividade exercida sobre a performance coral interrompendo-a, sobrepóe performances com orientações aurais diversas.

5. Em Electra temos também o párodo compartilhado de Electra com o coro (vv. 86-250), e quando da revelação da presença de Orestes, os irmãos vingadores promovem 
6. Justaposição diz respeito à uma sucessão de unidades discretas, enquanto que sobreposição se identifica com uma sucessão na qual as unidades perdem suas marcas iniciais e finais. A primeira tática estruturante tende a colocam em primeiro plano a horizontalidade; a segunda, a verticalidade. V. apêndice. um encontro verbo-musical truncado, um canto de triunfo suspendido, frente à possibilidade de entrada dos senhores do palácio(vv. 1232-1287). Mais complexa e espetacular é a cena da morte de Clitemnestra, uma ação cênica cantada entre o coro em cena, os gritos de Clitemnestra e a interação entre Orestes e Electra (vv. 1398-1441).A continuidade da ação é garantida pela integração de atos verbo-musicais.

6. Édipo em Colono também possui um párodo compartilhado com estrofes intercaladas onde o coro vem a conhecer os viajantes Édipo e Antígona. Entre os versos 833-886 temos um debate verbo-musical que apresenta a cena da captura das filhas de Édipo por parte de Creonte a máxima sobreposição de canto e fala marca os atos e as reaçôes do litigantes. No epirrema (vv. 1447-1499) o canto do corpo é intercalado com diálogo falado entre Édipo e Antígona. Sons de trovão demarcam e aproximam as partes sobrepostas. Note-se como a sobreposição das articulaçôes desenvolve uma flexibilidade das performances mais sonoramente marcadas.

Ou seja, enquanto em Ésquilo há a tendência de justaposição das partes através de blocos que apresentam bem distintos seus extremos iniciais e finais, em Sófocles temos a tendência à sobreposição das partes cantadas e não cantadas, de modo a se trabalhar com uma maior continuidade entre as partes distintas. Ao invés de exibir marcadas diferenças dominantes em cada bloco, Sófocles reúne os diferidos dispondo-os em sucessão e confronto ${ }^{6}$.

Dessa maneira, o efeito de limitação de conhecimento dos agentes dramáticos é enfatizado. Ao se sobrepor as performances, é a partir dessa aproximação que se torna relevante a diferente perspectiva que os agentes têm dos eventos dos quais participam. Quanto mais inseridos em uma homogeneidade articulatória (canto, fala), mas é marcada a distinção entre os que contracenam. A contracenação delineia o horizonte não interativo dos agentes dramáticos.

É em função desse contexto expressivo que a representação das figuras isoladas destaca-se tanto de uma anacrônica caracterização realista quanto de um essencialismo humanizante. Dentro dos limites de um espetáculo individual, composto através da aproximação e sobreposição de partes cantadas e 
não cantadas, o efeito de não concordância e diferenciação entre os agentes dramáticos, tanto entre agentes corais e não corais, encontra no isolacionismo de alguns personagens sua mais explícita realização. No extremo de extremos, até onde a sobreposição possibilita, as figuras isoladas trazem consigo a totalidade do movimento de sua delimitação. Dentro de uma dramaturgia musical, as figuras isoladas revertem para as especificidades dessa dramaturgia. Não se pode esconder o som. A redução das partes musicais revela a musicalidade mesma.

W.C. Scott denomina hiperformas o procedimento de Sófocles de, dentro da sobreposição de formas cantadas e não cantadas, manter efetiva a atuação modeladora da configuração sonora sobre a ação em cena (Scott 1986, 204-209). Ao invés da explícita e extensa performance musical, temos interrupções das performances cantadas gerando performances incompletas que exibem, inicialmente, o colapso imediato da organização das atividade aural do espetáculo. Contudo, com o prosseguir da performance podemos notar a posteriori a presença da configuração sonora que singulariza os desempenhos em cena.

Com a sobreposição das partes faladas e cantadas e a mútua apropriação de funçóes e formas por estas partes, temos uma produzida continuidade do espetáculo que aparentemente apaga as marcas de sua descontinuidade. Contudo, mesmo na sobreposição as marcas ainda estão visíveis e fornecem expectativas que serão completadas pela audiência. Contra a identidade entre articulador da representação e a própria representação, a não integridade imediata das partes cantadas e as figuras isoladas em cena complementam-se, ocasionando um espetáculo no qual a contracenação sem interação entre os agentes desencadeia uma atividade cognoscente da audiência mais envolvente que atravessa os séculos e nos traz aqui.

\section{BIBLIOGRAFIA}

Burton,R.B.W The Chorus in Sophocles Oxford University Press, 1980.

Court, B. Die Dramatische Technik des Aischylos Teubner, 1994.

Dawe, R.D. "Inconsistency of plot and character in Aeschylus" in PCPhS, 189, 1963, 21-62.

Easterling, P.E. "Character in Sophocles" in G\&R 20 (1973) 3-18. 
Gardiner, C.P. The Sophoclean Chorus: A Study of Character and Function Iowa city, 1986.

Herington, J. Aeschylus. Yale University, 1986

Joansen, H. FRIIS “Sophocles 1939-1959"Lustrum 7,1962,94-288.

Lesky, A . Greek Tragic Poetry. Yale University Press 1983.

Lloyd-Jones,H. e Wilson, N.G Sophoclis Fabulae Oxford University Press, 1990.

Mota, M. A dramaturgia musical de Ésquilo: investigaçôes sobre composição, realização e recepção de ficçôes audiovisuais. Brasília: Editora Universidade de Brasília, 2008.

Mota, M. Rumo ao drama: o teatro como fição audiovisual Inédito, 2003. v. www.marcusmota.com.br.

Russo, C.F. Aristophanes. An Author for the Stage. Routledge, 1994. Scott, W. C. Musical Design in Sophoclean Theater University Press of New England, 1996.

Sommerstein, A. H. Edição, tradução e notas As rẫs Aris\&Phillips, 1999.

Webster, T.B.L. An introduction to Sophocles. Clarendon Press, 1936.

Wilamowitz, T. Die dramatische Technik des Sofocles Berlin, 1917.

\section{Apêndice}

Para representar visualmente táticas de justaposição e sobreposição, apresento imagens abaixo. No primeiro exemplo, temos blocos em sequência, nos quais identificamos seus contornos iniciais e finais. No segundo exemplo, os blocos se encontram sobrepostos, tendo seus contornos finais e iniciais fundidos entre si. Veja-se também que as táticas manipulam tanto espaço quanto tempo, pois a sobreposiçáo intensifica a distribuiçãao e duração dos blocos.

Ex. 1.
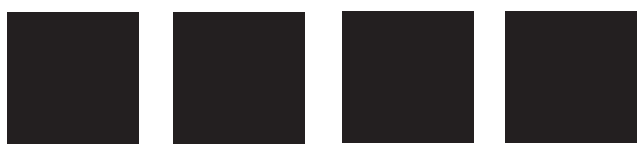

Ex. 2.

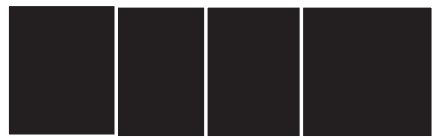

Recebido em março de 2013 Aprovado em agosto de 2013. 